\title{
Interaction of linear manno-oligosaccharides with three mannose-specific bulb lectins. Comparison with mannose/glucose-binding lectins *
}

\author{
Hanae Kaku and Irwin J. Goldstein \\ Department of Biological Chemistry, University of Michigan, Ann Arbor, Michigan 48109 (USA)
}

(Received June 3rd, 1991; accepted in revised form October 15th, 1991)

\begin{abstract}
Three new mannose-binding lectins, isolated from daffodil (NPA), amaryllis (HHA), and snowdrop (GNA) bulbs, are capable of precipitating with a linear mannopentaose (Man $\alpha 1$-3Man $\alpha 1$-3Man $\alpha 1$ $3 \mathrm{Man} \alpha 1-2 \mathrm{Man}$ ). NPA and HHA reacted strongly with the mannopentaose whereas GNA gave a precipitate only at concentrations $>500 \mu \mathrm{M}$. A phosphate group at C- 6 of the nonreducing terminal mannosyl group prevented precipitation in all three cases. The reduced $\left(\mathrm{NaBH}_{4}\right)$ mannopentaose, $\mathrm{Man}_{4}$ Man-ol, did not precipitate with GNA or NPA, but was active with HHA. This activity was lost when $\mathrm{Man}_{4}$ Man-ol was converted $\left(\mathrm{NaIO}_{4}\right.$ then $\mathrm{NaBH}_{4}$; mild acid hydrolysis of the reduced product) into trisaccharide derivatives. With $\alpha$-D-Man $p$-OMe the three lectins gave UV difference spectra having large positive peaks at $292-293$ and $283-284 \mathrm{~nm}$, and a small positive peak at $275 \mathrm{~nm}$, characteristic of tryptophanyl and tyrosyl residues. The association constants for the interaction with $\alpha$-D-Man $p$-OMe were very low (NPA, 86; HHA, 66; and GNA, $41 \mathrm{M}^{-1}$ ), but the lectins bound methyl $(1 \rightarrow 3)$ - $\alpha$-mannobioside with increased affinity ( $K$ for NPA 540 , for HHA 2400 , and for GNA 200 $\mathbf{M}^{-1}$ ). The bulb lectins lack binding sites for hydrophobic ligands, as judged by their failure to interact with the fluorescent probes 8-anilino-1-naphthalenesulfonic acid (ANS) and 6-p-toluidino-2-naphthalenesulfonic acid (TNS).
\end{abstract}

\section{INTRODUCTION}

Previously we have reported on the carbohydrate-binding specificity of a new class of mannose-binding lectins ${ }^{1,2}$ found in the bulbs of monocotyledonous plants $^{3,4}$. These lectins, present in the bulbs of the snowdrop (Galanthus nivalis, GNA) ${ }^{3}$, daffodil (Narcissus pseudonarcissus, NPA), and amaryllis (Hippeastrum hybr., HHA), are distinguished by their unique property of interacting solely with D-mannose; unlike the family of lectins from the legumes jack bean, pea, lentil, and broad bean (Vicia faba), they do not recognize D-glucose or $N$-acetyl-D-glucos-

Correspondence to: Professor I.J. Goldstein, Department of Biological Chemistry, University of Michigan, Ann Arbor, MI 48109, USA.

* This research was supported by NIH Grant GM 29470. 
amine. Recently we were surprised to find that the bulb lectins have the property of forming precipitates with a short chain manno-oligosaccharide, namely the mannopentaose Man $\alpha 1-3 \operatorname{Man} \alpha 1-3 \operatorname{Man} \alpha 1-3 \operatorname{Man} \alpha 1-2 \mathrm{Man}$. This report documents and expands that observation and its implications. A comparison of the properties of the bulb lectins with the mannose/glucose-binding lectins is also presented, together with observations on the binding affinities of the bulb lectins for methyl $\alpha$-mannoside and $\operatorname{Man} \alpha 1-3 \operatorname{Man} \alpha$-OMe, and on the lack of binding sites for hydrophobic ligands in these lectins.

\section{RESULTS}

The results of quantitative precipitation analysis of the interactions of mannopentaose and phosphorylated mannopentaose $\left(\mathrm{Man}_{5}\right.$ and P-Man ${ }_{5}$; structures and abbreviations are shown in Table I) with the mannose-binding lectins from daffodil (NPA), amaryllis (HHA), and snowdrop (GNA) are shown in Figs. 1 and 2. HHA reacted strongly and NPA moderately with $\operatorname{Man}_{5}$, whereas GNA reacted only at high concentrations ( $\geqq 500 \mu \mathrm{M}$ ); all three lectins failed to precipitate with P-Man 5 .

Interestingly, $\mathrm{NaBH}_{4}$-reduced $\mathrm{Man}_{5}$ ( $\mathrm{Man}_{4} \mathrm{Man}$-ol) still gave a moderately strong reaction with HHA, but failed to precipitate with GNA or NPA (Fig. 3). Moreover, periodate-oxidized then reduced $\mathrm{Man}_{5}$ before ( $\operatorname{seco}^{4}-\mathrm{Man}_{4}$-glycerol) and after ( $\mathrm{Man}_{5}$-glycerol) mild acid hydrolysis no longer formed a precipitate with HHA (data not shown).

Both the NPA- and HHA-Man 5 precipitation systems were inhibited by $\alpha$-D-Man $p$-OMe, concentrations of 8.2 and $10.8 \mathrm{mM}$, respectively, being required for $50 \%$ inhibition. These results demonstrate that both lectins interact in a specific manner with the mannosyl units in $\mathrm{Man}_{5}$.

The UV difference spectra of GNA induced by the addition of varying amounts of $\alpha$-D-Man $p$-OMe are shown in Fig. 4A. These spectra exhibited two positive peaks with maxima at $292-293$ and $283-284 \mathrm{~nm}$, and two negative peaks with maxima at 279 and $288 \mathrm{~nm}$, respectivcly. A small positive peak at $275 \mathrm{~nm}$ and the

TABLE I

Structures of the linear manno-oligosaccharides

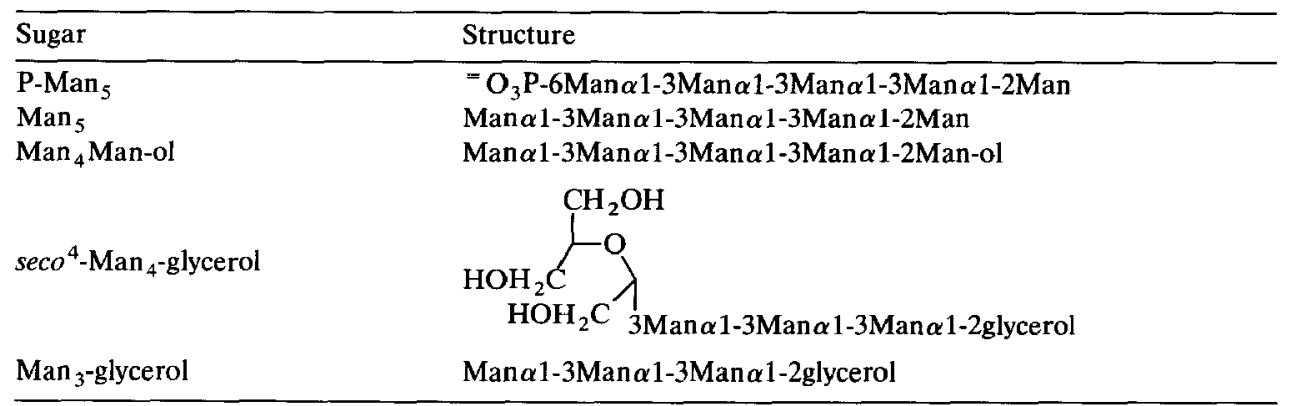



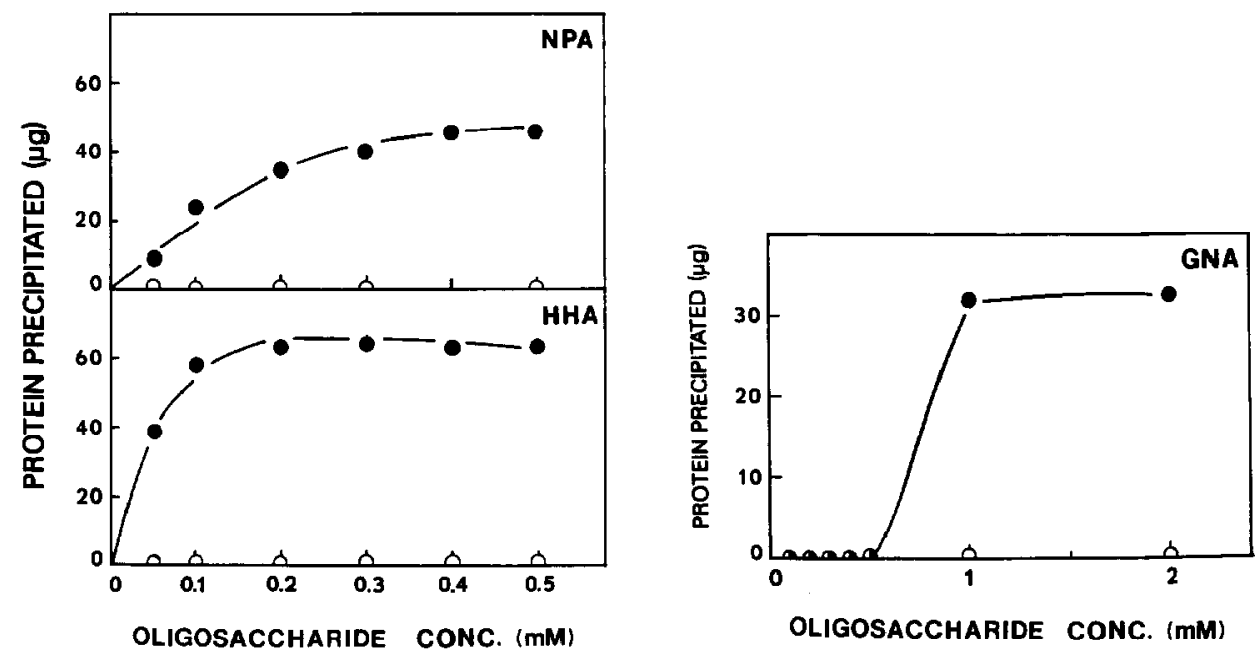

Fig. 1. (left) Quantitative precipitation curves of P-Man ${ }_{5}(0)$ and $\operatorname{Man}_{5}(\bullet)$ with NPA and HHA. The protein concentration was $50 \mu \mathrm{g} / 100 \mu \mathrm{L}$ in each case.

Fig. 2. (right) Quantitative precipitation of $P-M_{5}(O)$ and $\operatorname{Man}_{5}(\bullet)$ by GNA. The lectin protein concentration was $50 \mu \mathrm{g} / 100 \mu \mathrm{L}$.

negative peak at $279 \mathrm{~nm}$ appear on increasing the sugar concentration. Furthermore, protein denatured by treatment with $7 \mathrm{M}$ urea showed a difference spectrum (Fig. 4B) distinct from that of native lectin complexed with sugar. All three lectins displayed identical spectra with $\alpha$-D-Man $p$-OMe, and the intensities of the difference spectra were dependent on the concentration of sugar. The interaction of GNA with $\alpha$-D-Man $p$-OMe is presented in Fig. 5A, and in Fig. 5B the data are plotted according to the relationship ${ }^{5}$

$\frac{[S]}{A}=\frac{1}{A_{\max }} \cdot[S]+\frac{1}{A_{\max } \cdot K}$

where $K$ is the binding constant of the lectin-sugar complex, [S] is the concentration of sugar, $A$ is the absorption difference at chosen wavelengths, and $A_{\max }$ is the maximum absorption difference, obtained when all of the lectin is complexed with sugar. The binding constants of NPA, HHA, and GNA with $\alpha$-D-Man $p$-OMe and $\operatorname{Man} \alpha 1-3 \mathrm{Man} \alpha-\mathrm{OMe}$, calculated according to this relationship, are summarized in Table II.

\section{DISCUSSION}

Our results demonstrate that the mannose-binding lectins present in snowdrop, daffodil, and amaryllis bulbs are capablc of precipitating with certain linear manno-oligosaccharides. We already reported that NPA and HHA could precipitate with a synthetic linear $(1 \rightarrow 6)-\alpha$-D-mannan, and a $(1 \rightarrow 3)-\alpha$-D-mannan (dp 30) 

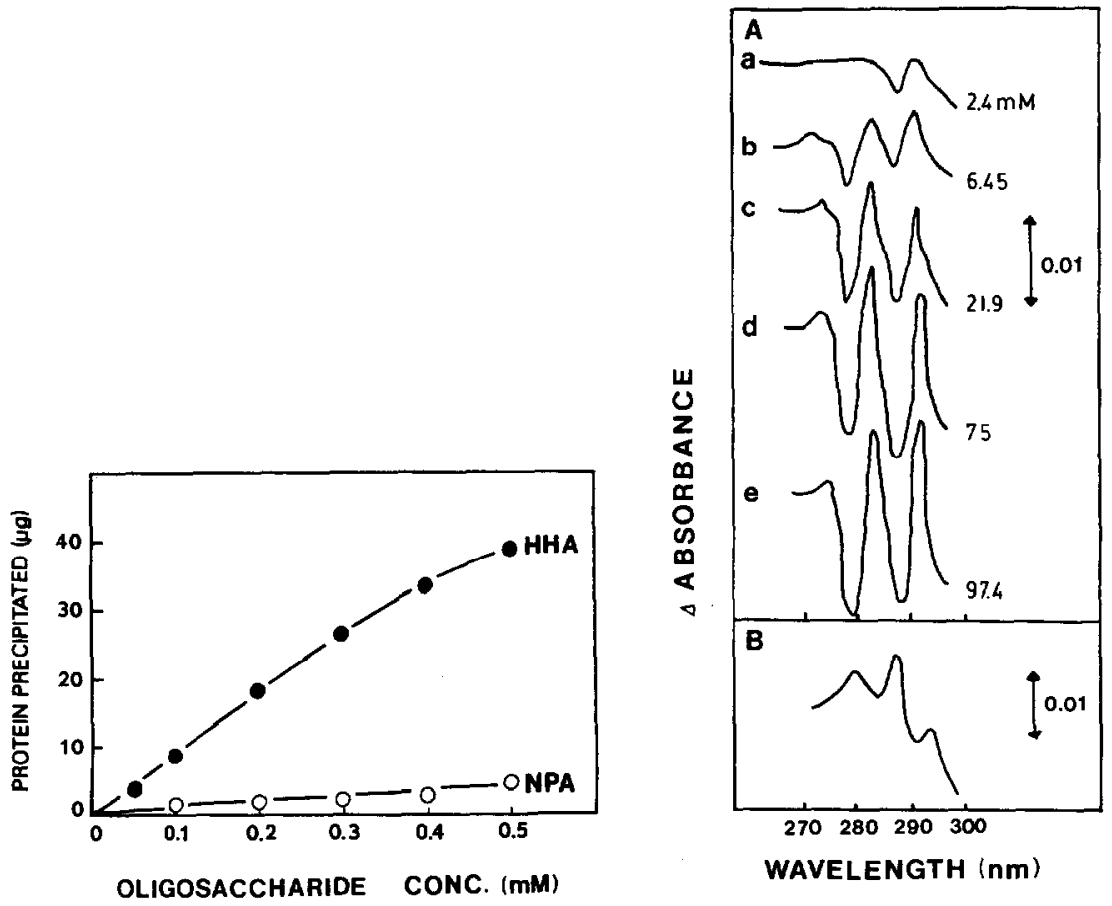

Fig. 3. (left) Quantitative precipitation of Man ${ }_{4}$ Man-ol by NPA (O) and HHA (๑). The protein concentration was $50 \mu \mathrm{g} / 100 \mu \mathrm{L}$ for NPA and IIIIA.

Fig. 4. (right) Ultraviolet difference spectra of GNA induced by the addition of $\alpha$-D-Man $p$-OMe (A) or by denaturation in $7 \mathrm{M}$ urea (B). The concentration of GNA was $1.2 \mathrm{mg} / \mathrm{mL}$ of PBS. The concentrations of $\alpha$-D-Man $p$-OMe were as indicated on the figure.

and its derivative modified at both termini by periodate oxidation then reduction, indicating that both NPA and HHA can recognize internal as well as terminal nonreducing mannosyl groups ${ }^{2}$. Interestingly, we also found that GNA was able to precipitate with these three linear synthetic mannans. This observation differs from that of a previous report ${ }^{1}$; GNA reacted only slightly with a linear $(1 \rightarrow 3)-\alpha$ D-mannan, from Trichosporon cutaneum ${ }^{6}$, that contains a small number of xylosyl and arabinosyl groups attached to its backbone. When the xylose and arabinose groups were removed from this mannan by treatment with periodate followed by reduction with $\mathrm{NaBH}_{4}$ and mild acid hydrolysis, GNA exhibited enhanced binding activity (data not shown). Thus, the three bulb lectins all have the capability of interacting with linear $\alpha$-(1 $\rightarrow 3)$ - and $\alpha$-(1 $\rightarrow 6)$-linked mannans.

In the present study, $\operatorname{Man}_{5}$ appeared to be the minimum sized oligomer capable of forming a precipitate with NPA. P-Man ${ }_{5}$, and also Man $_{4}$ Man-ol, failed to give a precipitate (Figs. 1 and 3), indicating that five intact, unmodified mannose residues are required. On the other hand, HHA reacted strongly with both $\mathrm{Man}_{5}$ and $\operatorname{Man}_{4}$-Man-ol (Figs. 1 and 3), but periodate oxidized, then reduced $\operatorname{Man}_{5}\left(\operatorname{seco}^{4}\right.$ $\mathrm{Man}_{4}$-glycerol), $\mathrm{Man}_{3}$-glycerol, and $\operatorname{Man} \alpha 1-3 \mathrm{Man} \alpha$-OMe were incapable of pre- 

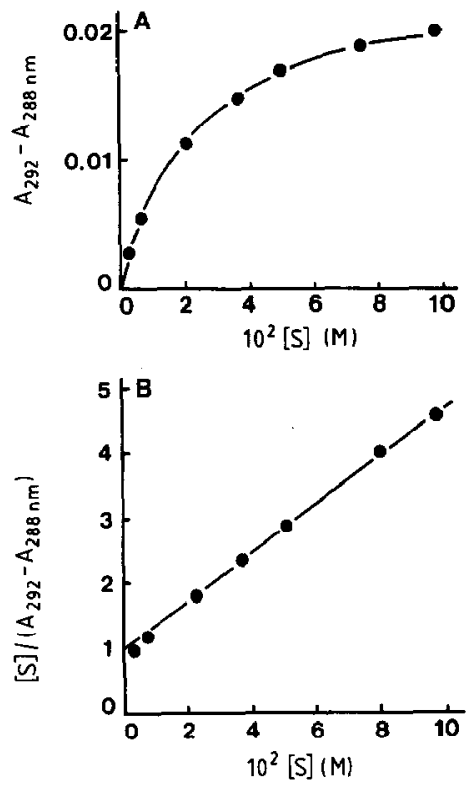

Fig. 5. Effect of the concentration of added $\alpha$-D-Man $p$-OMe (denoted by $[S]$ ) on the difference spectrum of GNA (A) and plot of $[S] /\left(A_{292}-A_{288}\right)$ vs. [S]. The solid line in plot B was calculated from a least-squares fit to the data. The binding constant was calculated from the intercept on the ordinate.

cipitating with this lectin (data not shown). These results suggest that four intact Man units are essential for HHA precipitation, and underscore a difference between HHA and NPA in their combining sites for linear manno-oligosaccharides. The third lectin, GNA, did not precipitate with $\mathrm{Man}_{5}$ until the concentration of the sugar was greater than $500 \mu \mathrm{M}$ (at $1 \mathrm{mM} \mathrm{Man}_{5}$ a pronounced precipitation reaction with GNA occurred).

Molecular models of $\mathrm{Man}_{5}$ and $\mathrm{Man}_{4}$ Man-ol are shown in Figs. 6A and B. The $(1 \rightarrow 3)_{-} \alpha$-D-mannan is in the extended ribbon structure ${ }^{7}$. The topographical sur-

TABLE II

Summary of binding constants for lectin-carbohydrate interactions

\begin{tabular}{lcc}
\hline Lectin & \multicolumn{2}{c}{ Binding constant $\left(\mathrm{M}^{-1}\right)$} \\
\cline { 2 - 3 } & $\alpha$-D-Man-OMe & Man $\alpha 1-3$ Man $\alpha$-OMe \\
\hline NPA & 89 & 540 \\
HHA & 66 & 2400 \\
GNA & 41 & 200 \\
Con A & $14000^{a}$ & \\
Vicia faba lectin & $500^{b}$ & \\
Lentil & $560^{c}$ & \\
\hline
\end{tabular}

${ }^{a}$ From So and Goldstein ${ }^{17}$ by equilibrium dialysis. ${ }^{b}$ From Matsumoto et al. ${ }^{19}$ by UV difference spectroscopy. 'c From Stein et al. ${ }^{24}$ by equilibrium dialysis. 


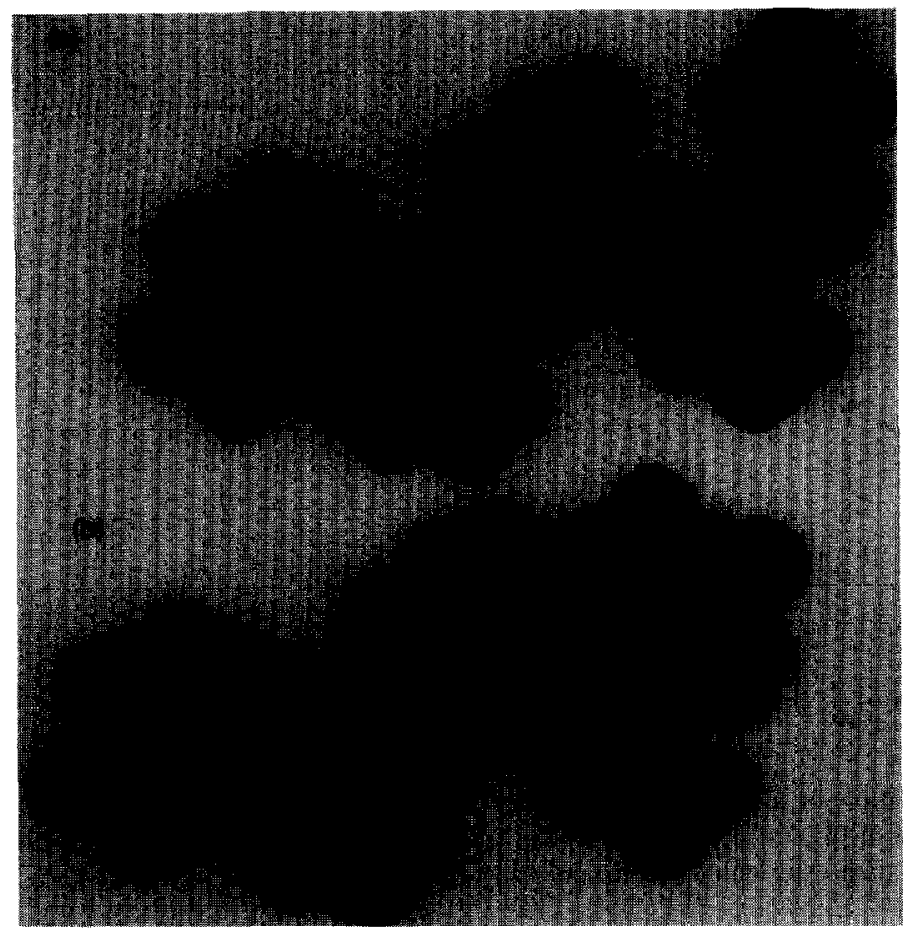

Fig. 6. Computer-graphic models of $\operatorname{Man}_{4} \operatorname{Man}-o l(a)$ and $\operatorname{Man}_{5}$ (b).

face formed by the hydroxyl groups at C-2, C-4, and C- 6 of each mannosyl residue, which form the loci for lectin binding, is rotated $\sim 60^{\circ}$ for each sugar residue. It is reasonable to assume that two multivalent lectin molecules interact with each mannopentaose molecule. We speculate that the nonreducing terminal $\alpha$-mannosyl group represents one lectin binding locus and the second or third $\alpha$-mannosyl group from the reducing end the second locus. As already indicated a phosphate residue on the nonreducing terminal mannose group precludes binding by the three bulb lectins.

Interestingly, it was possible to partially inhibit $\mathrm{HHA}-\mathrm{Man}_{5}$ precipitation by the addition of GNA; $50 \mu \mathrm{g}$ of GNA (the system also contained $50 \mu \mathrm{g}$ of HHA) gave $20 \%$ inhibition of precipitation, demonstrating that HHA has a stronger binding affinity for $\mathrm{Man}_{5}$ than GNA.

Recently, Brewer and coworkers ${ }^{8-11}$ reported that Con A, classified as a mannose/glucose-specific lectin, can precipitate with oligosaccharides containing bisected hybrid, complex, and high-mannose type chains. All these oligosaccharides contain at least two nonreducing terminal sugar groups. We confirmed a previous report that Con $\mathrm{A}$ does not react with a synthetic $\alpha-(1 \rightarrow 3)$-linked mannan ${ }^{12}$, and we found that Con A did not precipitate with $\mathrm{Man}_{5}$ and P-Man (data not shown). Moreover, pea lectin (PSA) also failed to precipitate with the 
synthetic linear $\alpha$-(1 $\rightarrow 3)$-linked mannan. This is in accord with the well-known generalization that binding to both Con A and PSA generally requires terminal mannose units. In this regard, we observed that Con A binds strongly to the synthetic branched trisaccharide $\operatorname{Man} \alpha 1-3(\operatorname{Man} \alpha 1-6) \operatorname{Man} \alpha-\mathrm{OMe}^{13}$. The affinity is 42 times greater than that for $\alpha$-D-Man $p$-OMe, a finding made previously by Carver et al. ${ }^{14}$ and Brewer et al. ${ }^{15}$ using nuclear magnetic relaxation dispersion (NMRD), X-ray crystallographic refinement techniques based on glycopeptide coordinates obtained from ${ }^{1} \mathrm{H}-\mathrm{NMR}$ measurements ${ }^{14}$, and hemagglutination-inhibition analysis ${ }^{15}$. However, the trisaccharide failed to precipitate with Con A, as reported by Bhattacharyya et al. ${ }^{11}$. HHA is also unable to precipitate with Man $\alpha$ 1-3(Man $\alpha 1-6)$ Man $\alpha$-OMe.

It is perhaps relevant to this study to note that Springer and Desai ${ }^{16}$ reported in 1971 that the eel agglutinin gave a typical precipiting curve with 3- $O$-methyl-Dfucose and 3-O-methyl-D-galactose, which suggests that the size of the binding site of the eel lectin may be smaller than a monosaccharide unit. However, the mechanism whereby the eel lectin precipitates the 3-O-methyl monosaccharides is undoubtedly different from that of the bulb lectins' precipitation reaction.

$\mathrm{Man}_{5}$ inhibited the Con A-dextran B-1355 interaction, a $1 \mathrm{mM}$ concentration being required for $50 \%$ inhibition, which makes it 4 and 30 times less potent than $\alpha$-D-Man-OMe and Man $\alpha 1-3 \mathrm{Man}-\mathrm{OMe}$, respectively. This result suggests that the hydroxyl groups of the terminal mannosyl unit with which Con A interacts are not as accessible in the $\alpha$-(1 $\rightarrow 3)$-linked mannopentaose as in $\alpha-(1 \rightarrow 2)$-linked manno-oligosaccharides ${ }^{12}$.

In UV difference spectroscopy studies we observed that the interaction of the three bulb lectins with the methyl glycosides of mannose and $(1 \rightarrow 3)-\alpha$-mannobiose gave two large positive peaks at $292-293$ and $283-284 \mathrm{~nm}$, and also exhibited a small peak at $275 \mathrm{~nm}$ (Fig. 4A). Matsumoto et al. ${ }^{5}$ reported that interaction of several lectins (e.g., Lens culinaris, Sophora japonica, Solanum tuberosum, and wheat germ with their carbohydrate ligands generated UV difference spectra with peaks at $292 \mathrm{~nm}$ and 284-287 nm, which arc characteristic of a tryptophanyl residue, and that peanut lectin also produced two peaks at $285 \mathrm{~nm}$ and $279 \mathrm{~nm}$, indicative of perturbation of tyrosyl residues. However, the shapes of the UV difference spectra of the three mannose-binding bulb lectins differ from those of these previous reports, and are characteristic of both tryptophanyl and tyrosyl residues.

All three mannose-binding lectins (NPA, HHA, and GNA), have very low association constants with $\alpha$-D-Man $p$-OMe $\left(89,66\right.$, and $41 \mathrm{M}^{-1}$, respectively), as shown in Table II. These association constants are 160-500 times lower than that of Con A with $\alpha$-D-Man-OMc as detcrmined by equilibrium dialysis ${ }^{17}$ and frontal analysis on an affinity column ${ }^{18}$, and 6- to 12-fold less than that of Vicia faba agglutinin as determined by the same methodolngy ${ }^{19}$. On the other hand, the methyl $\alpha$-glycoside of Man $\alpha 1$-3Man bound with increased affinity to NPA, HHA, and GNA, the binding constants being 540,2400 , and $200 \mathrm{M}^{-1}$, respectively. These 
values are 5 to 6 times greater than $K$ for $\alpha$-D-Man $p$-OMe in the case of NPA and GNA, and 36 times higher than $K$ for $\alpha$-D-Man $p$-OMe in the case of HHA. The much higher binding activity for the mannobiose of HHA, as compared with NPA and GNA, accords with the strong interaction of HHA with $\mathrm{Man}_{5}, \mathrm{Man}_{4}$ Man-ol, and the GP-V fraction of ovalbumin ${ }^{2}$.

We also investigated the three lectins for their capacity to bind hydrophobic ligands by fluorescence spectroscopy using 8-anilino-1-naphthalenesulfonic acid (ANS) and 6-p-toluidino-2-naphalenesulfonic acid (TNS). No fluorescence enhancement was seen in any of these experiments, suggesting that these bulb lectins do not have binding sites for hydrophobic ligands in their molecular structures. Robert and Goldstein ${ }^{20}$ reported that binding sites for hydrophobic ligands are possessed by most legume lectins (including Con $\mathrm{A}$ and the lentil and pea lectins), as well as some nonlegume agglutinins (e.g., potato lectin, Ricinus communis agglutinin I, and wheat germ agglutinin). These observations further differentiate the three bulb lectins from the previously known mannose/glucose-binding lectins.

In summary, the three new mannose-specific bulb lectins exhibit a novel sugar-binding specificity, and also display fine differences among themselves in their sugar-recognition properties. Lectins NPA and HHA exhibit remarkable capacity to precipitate with linear mannopentaose at low sugar concentrations, and HHA is unique in its ability to precipitate with a $(1 \rightarrow 3)$ - $\alpha$-manno-oligosaccharide having only four intact mannose residucs. Prcliminary studies indicate that these three lectins show substantial homology among their amino acid sequences (unpublished data). It will be of great interest to determine the relationship between their sugar-binding specificity and amino acid sequence.

\section{EXPERIMENTAL}

The snowdrop (GNA), daffodil (NPA), and amaryllis (HHA) lectins were isolated from extracts of their bulbs by affinity chromatography on immobilized mannose as previously reported ${ }^{3,4}$. Concanavalin A (Con A) was purified by the procedure of Agrawal and Goldstein ${ }^{21}$. Pea lectin (PSA) was the gift of Dr. J. P. Carver of the University of Toronto.

The synthetic phosphorylated mannopentaose ( $\mathrm{O}_{3} \mathrm{P}-6 \mathrm{Man} \alpha 1-3 \mathrm{Man} \alpha 1$ 3Man $\alpha 1-3 \operatorname{Man} \alpha 1-2 \mathrm{Man}$ ) was the generous gift of Dr. Y.C. Lee, the Johns Hopkins University, Baltimore, MD. Methyl $\alpha$-D-mannoside ( $\alpha$-D-Man $p$-OMe) and Man $\alpha 1-3$ Man $\alpha$-OMe were obtained from Pfanstiehl Laboratories, Inc., Waukegan, IL and Sigma Chemical Co., St. Louis, MO, respectively.

8-Anilino-1-naphthalenesulfonic acid (ANS) was obtained from Eastman-Kodak, Rochester, NY and recrystallized from $\mathrm{H}_{2} \mathrm{O} ; 6$-p-toluidino-2-naphthalenesulfonic acid (TNS) was obtained from the Sigma Chemical Co., St. Louis, MO.

Preparation of the penta-, tetra-, and tri-saccharides. - Mannopcntaose $\left(\mathrm{Man}_{5}\right.$, $2 \mathrm{mg}$ ) was prepared from phosphorylated mannopentaose (P-Man ${ }_{5}$ ) by incubation with $10 \mu \mathrm{L}$ of alkaline phosphatase (4 units, Type XXX from unweaned-calf 
intestinal mucose, Sigma) in $0.15 \mathrm{M}$ Tris $\cdot \mathrm{HCl}$ buffer (pH 8.0 , containing $1 \mathrm{mM}$ $\mathrm{MgCl}_{2}$ ) at $37^{\circ}$ for $15 \mathrm{~h}$. The reaction product was loaded onto a sequence of two columns containing Amberlite IR-120 $\left(\mathrm{H}^{+}\right)$and Dowex 1- $\mathrm{X8}\left(\mathrm{CH}_{3} \mathrm{COO}^{-}\right)$ion-exchange resins, respectively, and eluted with water. The sugar-positive, excluded fractions from the column were combined and lyophilized. Carbohydrate concentrations were determined by the phenol- $\mathrm{H}_{2} \mathrm{SO}_{4}$ method ${ }^{22}$.

Mannotetraosylmannitol $\left(\mathrm{Man}_{4} \mathrm{Man}-\mathrm{ol}\right)$ was prepared by the reduction of $\mathrm{Man}_{5}$ with $0.1 \% \mathrm{NaBH}_{4}$ at $4^{\circ}$ for $15 \mathrm{~h}$. The reduced material was purified on a Bio-Gel $\mathrm{P}-2$ gel-filtration column $(0.9 \times 60 \mathrm{~cm})$ by elution with $\mathrm{H}_{2} \mathrm{O}$; sugar-positive fractions were combined and lyophilized.

Periodate-oxidized then reduced $\mathrm{Man}_{5}\left(\mathrm{seco}^{4}-\mathrm{Man}_{4}{ }^{-}\right.$-glycerol, structure shown in Table I) was prepared by the Smith-degradation procedure as follows: $\operatorname{Man}_{5}(2$ $\mathrm{mg}$ ) was incubated with $50 \mathrm{mM} \mathrm{NaIO}$ solution in the dark at $4^{\circ}$ for $72 \mathrm{~h}$. After destruction of excess periodate by the addition of ethylene glycol, the oxidized product was reduced overnight with $\mathrm{NaBH}_{4}$ at $4^{\circ}$, then purified over Bio-Gel P-2. Sugar-positive fractions were combined and lyophilized.

Mannotriosylglycerol $\left(\mathrm{Man}_{3}\right.$-glycerol) was generated by treatment of seco $^{4}$ $\mathrm{Man}_{4}$-glycerol with $0.1 \mathrm{M} \mathrm{H}_{2} \mathrm{SO}_{4}$ at room temperature for $16 \mathrm{~h}$ followed by neutralization with $0.2 \mathrm{M} \mathrm{NaOH}$ and purification over Bio-Gel P-2 as described above. The structures of $\mathrm{seco}^{4}$-Man ${ }_{4}$-glycerol and $\mathrm{Man}_{3}$-glycerol were confirmed by the determination of glycerol, following treatment of the oligosaccharides with $0.2 \mathrm{M} \mathrm{H}_{2} \mathrm{SO}_{4}$ at room temperature for $15 \mathrm{~h}$. The measurement was done with a glycerol analysis kit (Boehringer Mannheim Biochem).

The purity of all oligosaccharides was established by TLC (solvent, 10:2:3 $n$-propanol-nitromethane- $\mathrm{H}_{2} \mathrm{O}$ ).

Quantitative precipitation assays. - These were carried out by a microprecipitation technique ${ }^{12}$. Lectin (NPA, HHA, or GNA, $50 \mu \mathrm{g}$ ) was combined with varying amounts of manno-oligosaccharide in a total volume of $100 \mu \mathrm{L}$ of $10 \mathrm{mM}$ phosphate buffer, $\mathrm{pH} 7.2$, containing $0.1 \mathrm{mM} \mathrm{CaCl}_{2}, 0.04 \% \mathrm{NaN}_{3}$, and $150 \mathrm{mM}$ $\mathrm{NaCl}$. After incubation at $37^{\circ}$ for $1 \mathrm{~h}$, the mixtures were kept at $4^{\circ}$ for 2 days, and centrifuged at $8800 \mathrm{~g}$ for $10 \mathrm{~min}$. Protein in the precipitates was determined by Lowry's method ${ }^{23}$ using bovine serum albumin (BSA) as standard.

Ultraviolet difference spectroscopy. - Difference spectra (lectin- $\alpha$-D-Man $p$-OMe or $-\operatorname{Man} \alpha 1-3 \operatorname{Man} \alpha$-OMe versus lectin) were recorded on a Cary 219 recording spectrophotometer. The concentrations of GNA, NPA, and HHA were 1.2, 0.49 , and $0.5 \mathrm{mg}$ per $\mathrm{mL}$, respectively. Measurements were made in a $1-\mathrm{cm}$ cell at $25^{\circ}$. To determine the difference spectrum of denatured GNA, a solution of GNA in 7 $M$ urea was placed into one compartment of a Yankeelov cuvette, and phosphatebuffered saline (PBS) was pipetted into the second compartment. A second cuvette was prepared with GNA-PBS in one compartment and $7 \mathrm{M}$ urea in the second compartment.

Fluorescence spectra. - Fluorescence spectra were determined as previously described by Roberts and Goldstein ${ }^{20}$, using an SLM 8000 C spectrofluorometer 
equipped with an MC-320 monochromator controller and a microcomputer (SLM Instruments, Inc., Urbana, IL).

\section{ACKNOWLEDGMENTS}

We wish to thank Dr. Y.C. Lee (the Johns Hopkins University) for his gift of phosphorylated mannopentaose. We thank Dr. L.M. Schopfer (University of Michigan) for help in performing the UV difference spectroscopy study. We also thank Murray Ratcliffe for helping us with the computer-graphic models of $\mathrm{Man}_{5}$.

\section{REFERENCES}

1 N. Shibuya, I.J. Goldstein, E.J.M. van Damme, and W.J. Peumans, J. Biol. Chem., 263 (1988) 728-734.

2 H. Kaku, E.J.M. van Dammc, W.J. Peumans, and I.J. Goldstein, Arch. Biochem. Biophys., 279 (1990) 298-304.

3 E.J.M. van Damme, A.K. Allen, and W.J. Peumans, FEBS Lett., 215 (1987) 140-144.

4 E.J.M. van Damme, A.K. Allen, and W.J. Peumans, Physiol. Plant., 73 (1988) 52-57.

5 I. Matsumoto, A. Jinbo, H. Kitagaki, A.M. Golovtchenko-Matsumoto, and N. Seno, J. Biochem. (Tokyo), 88 (1980) 1093-1096.

6 P.A.J. Gorin and J.F.T. Spencer, Can. J. Chem., 45 (1967) 1543-1649.

7 J.F. Kennedy and C.A. White, Bioactive Carbohydrates, Ellis Horwood, Ltd., Chichester, England, 1983, pp. 46-50.

8 L. Bhattacharyya and C.F. Brewer, Biochem. Biophys. Res. Commun., 137 (1986) 670-674.

9 L. Bhattacharyya and C.F. Brewer, Biochem. Biophys. Res. Commun., 141 (1986) 963-967.

10 L. Bhattacharyya, C. Ceccarini, P. Lorenzoni, and C.F. Brewer, J. Biol. Chem., 262 (1987) $1288-1293$.

11 L. Bhattacharyya, M. Haraldsson, and C.F. Brewer, J. Biol. Chem., 262 (1987) 1294-1299.

12 L.L. So and I.J. Goldstein, J. Biol. Chem., 243 (1968) 2003-2007.

13 H. Kaku, I.J. Goldstein, and S. Oscarson, Carbohydr. Res., 213 (1991) 109-116.

14 J.P. Carver, A.E. Mackenzie, and K.D. Hardman, Biopolymers, 24 (1985) 49-63.

15 C.F. Brewer, L. Bhattacharyya, R.D. Brown, III, and S.H. Koenig, Biochem. Biophys. Res. Commun., 127 (1985) 1066-1071.

16 G.F. Springer and P.R. Desai, Biochemistry, 10 (1971) 3749-3761.

17 L.L. So and I.J. Goldstein, Biochim. Biophys. Acta, 165 (1968) 398-404.

18 Y. Oda, K. Kasai, and S. Ishii, J. Biochem. (Tokyo), 89 (1981) 285-296.

19 I. Matsumota, Y. Uehara, A. Jimbo, and N. Seno, J. Biochem. (Tokyo), 93 (1983) 763-769.

20 D.D. Robert and I.J. Goldstein, Arch. Biochem. Biophys., 224 (1983) 479-484.

21 B.B.L. Agrawal and I.J. Goldstein, Biochem. Biophys. Acta, 147 (1967) 262-271.

22 M. Dubois, K.A. Gilles, J.K. Hamilton, P.A. Rebers, and F. Smith, Anal. Chem., 28 (1956) 350-356.

23 O.H. Lowry, N.J. Rosebrough, A.L. Farr, and R.J. Randall, J. Biol. Chem., 193 (1951) 265-275.

24 M.D. Stein, I.K. Howard, and H.J. Sage, Arch. Biochem. Biophys., 146 (1971) 353-355. 